society's understanding of our environmental travails and the institutional inertia that ensues from ignorance (or ignore-ance). Instead of lengthy lists of obvious safeguard measures such as switching off unnecessary lights (even while leaving computers and microwaves on standby), the Ehrlichs take us through the systems, political and otherwise, that we deploy to run our societies. They highlight the cultural disconnection between what most people think is going on (the stock market, say) and the environmental breakdowns that will eventually prove much more important. The technological underpinnings of our societies have far outstripped our cultural understanding. "A 747 jetliner embodies much more information...than all of the DNA packed into the pilots' cells... The transition to a state of ubiquitous cultural ignorance has occurred in an evolutionary twinkling of an eye, and humanity is having great difficulty dealing with it." This applies particularly to those technologies that promise much but inflict severe harm on the human cause.

The book is not only about the usual environmental problems. It tackles sources of problems, such as cultural roadblocks, group (mis-)behaviour, contagion of attitudes, "stickiness" of thinking, social discontinuities, special interests and other forms of social rigidity and perversity. The Ehrlichs also present plenty of solutions through their assessments of collective action, optimized governance, pre-emptive initiatives, ethical imperatives and huge changes in personal and community outlooks. This material makes up the bulk of the book, in contrast with the Ehrlichs' earlier writings. Here they deal with issues that deserve intensive analysis but receive comparatively little research.

Not surprisingly, the Ehrlichs suggest that the Millennium Development Goals proposed by the United Nations in 2000 - to tackle malnutrition, child mortality, female illiteracy and water shortages, for examplebe supplemented by a Millennium Assessment of Human Behaviour. Such a measure could be founded on the idea that we live at a time when what is idealistic is swiftly converging with what is realistic.

This listing of the principal components of the Ehrlichs' message may sound a trifle earnest, but the book's spirit is saved by the jaunty style that informs the text. The authors are masters at finishing paragraphs with one-liners, such as: "We have utterly changed our world; now we'll have to see if we can change our ways." Better still, the style suggests that the authors are not a whit dispirited by their message; rather, it implies that they sense not only profound problems but superb opportunities. The Ehrlichs have often been called the ultimate pessimists, but their book is, frankly, heartening.

In short, they have spread their conceptual net much wider than before. The book is decidedly new and different. And as a final bonus, it contains more than 700 references and 1,000 notes.

Norman Myers is honorary visiting fellow at Green College, Oxford University, Upper Meadow, Old Road, Oxford OX3 8SZ, UK.

\section{Family values}

\section{More than Kin and Less than Kind: the Evolution of Family Conflict}

by Douglas W. Mock

Harvard University Press: 2004. 352 pp. $\$ 27.95$

\section{H. Charles J. Godfray}

The private life of the Verreaux's (or black) eagle, a spectacular raptor of the drier parts of Africa, does not exactly embody Victorian family values. The female nearly always lays two eggs, a few days apart, which hatch into two chicks, one a little bigger than the other. As soon as the smaller hatches it is turned upon by its sibling, which attacks it viciously, the assault almost invariably leading to death. In one nest that was continuously watched by the ornithologist Valerie Gargett, the bigger chick pecked its nestmate 1,569 times in its brief 72-hour existence. Throughout this period, the parents did nothing to intervene. Ornithologists used to call this phenomenon 'cainism' but today use the less poetic, but less sexist, term 'siblicide'. Obligate siblicide occurs in some other raptors as well, and in species of boobies, penguins, egrets and pelicans. Less extreme forms of siblicide are much more widespread in birds: usually the parent produces a hierarchy of chicks and, when conditions are less than perfect, the runt dies, either because its siblings passively deprive of it food, or through more direct attacks.

In More than Kin and Less than Kind, Douglas Mock surveys sibling conflict in birds, and gives a more limited number of examples from other groups of animals and plants. He charts how biologists' views of siblicide have evolved over the years: it has been considered simply an aberration, and also a means of population control for the benefit of the species. The latter explanation became untenable when evolutionists in the 1960s realized the importance of thinking about how selection operates at the individual level. David Lack's view prevailed: parents overproduce young so that they can capitalize on bumper food years when everyone survives, with siblicide being an efficient mechanism to adjust litter size in poor years.

This still does not explain obligate siblicide, which for a long time was controversial. But now there is a general consensus that obligate siblicide is an insurance mechanism to guard against egg infertility or the very early death of a chick: in the species in which it occurs, an infertile single egg may mean a completely wasted breeding season.

Although extreme forms of sibling conflict receive most attention, Mock also discusses more moderate forms of squabbling (informed, perhaps, by his own experience as the youngest of four brothers), as well as conflicts between parents and offspring, and between mothers and fathers.

Mock has a lively and engaging style, and the skill to explain complex ideas from kin selection and related fields intelligibly without being patronizing. He is best known for his work on siblicide in egrets and herons, and his accounts on the one hand of long hours of fieldwork with the birds steadfastly refusing to behave as his hypotheses predict, and on the other of sudden insights from watching family interactions in the nest, are both inspiring and ring true.

The one area where I think he goes astray is parent-offspring conflict, which he views as an interesting theory that, with a few notable exceptions, has failed to produce much insight. The theory is based on Robert Trivers' argument that natural selection operates differently on genes expressed in

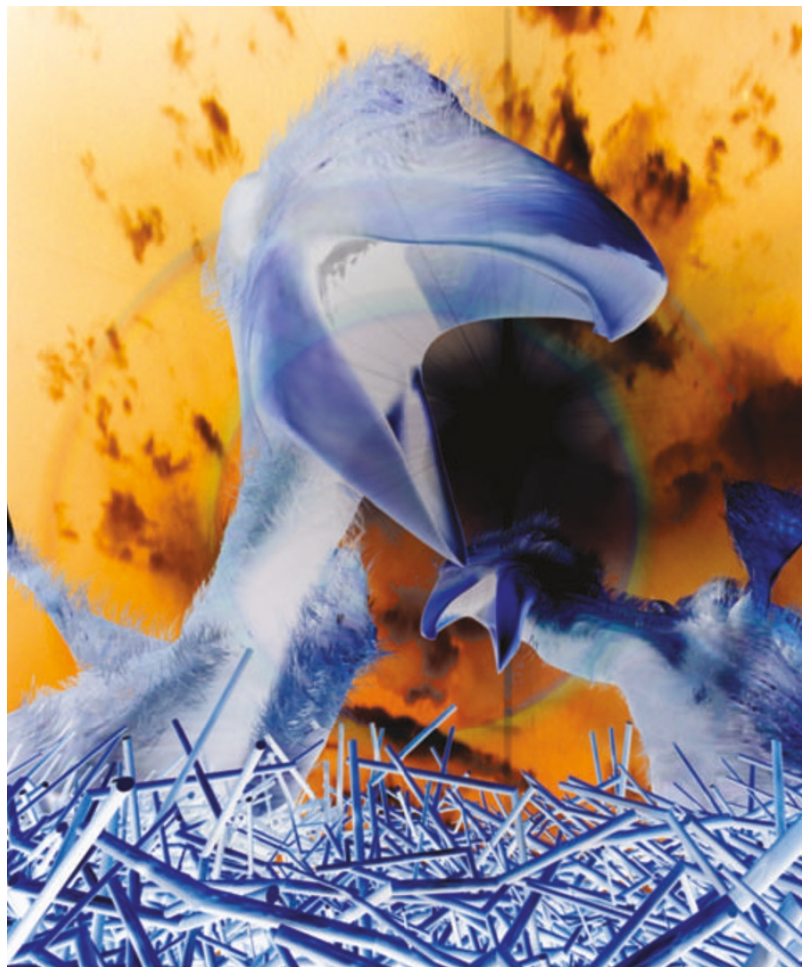




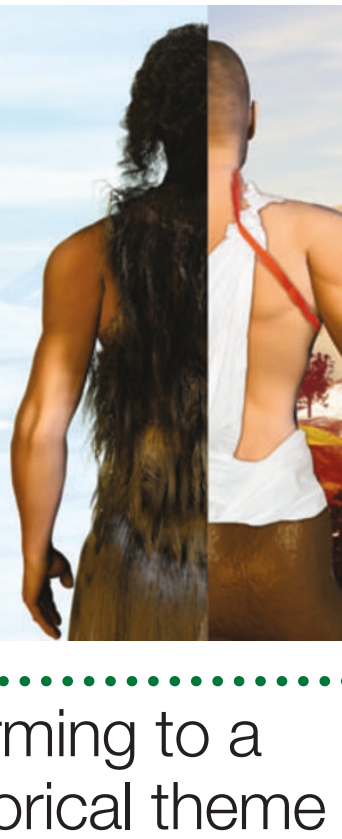
sponding reduction in parental fitness. I think this is far too narrow an interpretation, and results from a failure to distinguish between the genetic battleground identified by Trivers, and the resolution of the conflict that we see in nature.

For example, it has been argued that the presence of parent-offspring conflict means that the only evolutionarily stable way in which young can communicate their requirements for food to their parents is by using costly signals. This would explain why the begging calls of baby birds may be energetically expensive to produce, or risk attracting predators. If true, the theory has told us something new about a situation where the optimum outcome for parents is achieved, though at a cost. Mock says little about this type of honest signalling by offspring, and in places is, I think, unfairly dismissive. This is a shame, as these ideas can explain many of the same phenomena as sibling conflict, and the two processes almost certainly operate together. Behavioural ecologists such as Mock have pointed to the difficulty of testing honest-signalling theory, but I think this should be viewed as a challenge rather than a reason to dismiss it.

With this one caveat, Mock has done a superb job in bringing a large area of contemporary behavioural ecology to both a biological and a general audience. It will stimulate a new generation of fieldworkers and inspire theoreticians to try to understand the complex interplay of natural selection acting simultaneously on different members of the family. For a general reader, it will explain how modern evolutionary theory is tested in the field and give a real flavour of the life a field biologist. It deserves to be read by everyone interested in the evolution of family life.

Charles Godfray is at the NERC Centre for Population Biology, Imperial College London,

Silwood Park Campus, Ascot, Berkshire SL5 7PY, UK.

\section{(}

Warming to a historical theme

\section{The Long Summer: How Climate Changed Civilization \\ by Brian Fagan \\ Granta/Basic Books: 2004. 284pp. £20/\$26 \\ Jeremy A. Sabloff}

Archaeology has numerous goals, which include constructing histories of peoples' cultures through space and time, offering an appreciation of the achievements of past civilizations, and providing historical contexts, both cultural and ecological, for modern events and processes. Writing about such issues for the public can be a challenge, but Brian Fagan is one of the world's most accomplished and prolific popularizers of this complex discipline. As he has shown in a variety of books, he has the knack of making arcane archaeological information accessible to broad audiences. Coupled with his broad knowledge of world prehistory, this skill allows him to show how the distant past is relevant to current concerns.

One of the most pressing concerns today is global climate change. In The Long Summer, Fagan provides an enlightening context for this key modern problem through a clearheaded discussion of the past 15,000 years of climatic warming, which has been enriched by great advances in climatology. He goes on to show how this climatic trend has influenced, but not determined, the development of complex civilizations.

Fagan states that "human relationships to the natural environment and short-term climatic change have always been in flux", and that we have become increasingly vulnerable to the effects of climate change, thanks to population growth, urbanization and the global spread of industry. He argues that our attempts "to cushion ourselves against smaller, frequent climate stresses...have consistently made us more vulnerable to rarer but larger catastrophes". This argument

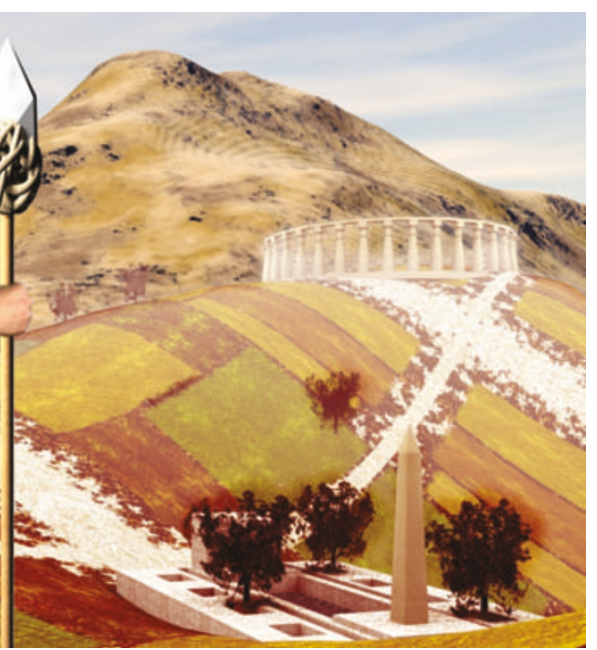

leads him to conclude that: "the present problem of global warming is neither proof of late capitalism's intent to commit industrial-strength sins against Mother Earth nor a hallucination imposed on the world by anti-business activists. It is simply a reflection of the scale of our vulnerability, the scale on which we must now think and act."

The environmental climate trajectory that Fagan describes is not a simple one; it has numerous short and long perturbations. The number of places, environmental events and cultures discussed can be daunting and occasionally confusing, and the complex story sometimes seems to get the better of even such a skilled storyteller as Fagan. But perseverance pays off, as Fagan manages to draw the diverse pieces into a coherent narrative and keep the reader on track. Moving forwards in time, Fagan examines the development of cultural complexity in selected time periods from 15,000 years ago to the present day, and in different regions of the globe from the Near East to the Andes.

Fagan offers many examples of how changes in climate have influenced cultures from hunters and gatherers to complex civilizations. One of the common factors is that environmental shifts in one region of the world can have profound effects in distant regions of the globe. For instance, the collapse of the Laurentide glacier in northern Canada around $6200 \mathrm{BC}$ had profound affects in the eastern Mediterranean and Anatolia, even triggering a drought lasting four centuries, which in turn had a major cultural impact on Anatolia.

Fagan also offers gripping examples of the key role of climatic change in such diverse topics as the rise of settled villages in the Near East some 11,000 years ago, the early growth of cities in ancient Sumer and Egypt in the fourth millennium BC, and the fall of the Roman Empire by the end of the fifth century AD.

Experts in different areas may take issue with Fagan over the details of the changes in the regions that they know best. Clearly Fagan has had to paint with a broad brush, 